\title{
Managing aflatoxin in smallholder groundnut production in Southern Africa: Paired comparison of the Windrow and Mandela cock techniques
}

Limbikani Matumba $^{1 *}$, Lazarus Singano $^{2}$, Bruno Tran $^{3}$, Mweshi Mukanga $^{4}$, Beatrice Makwenda ${ }^{5}$, Wycliffe Kumwenda ${ }^{5}$, Sharif Mgwira ${ }^{6}$, Sam Phiri ${ }^{5}$, Frazer Mataya ${ }^{5}$, Talentus Mthunzi ${ }^{7}$, Sharon Alfred $^{7}$, Tshilidzi Madzivhandila ${ }^{7}$, Jonas Mugabe $^{8}$, Ben Bennett $^{3}$, Tim Chancellor $^{3}$

${ }^{1}$ Lilongwe University of Agriculture and Natural Resources (NRC Campus), Lilongwe, Malawi;

${ }^{2}$ Department of Agricultural Research Services, Chitedze Research Station, Lilongwe, Malawi;

${ }^{3}$ Natural Resources Institute - University of Greenwich, Chatham, Maritime Kent, UK; ${ }^{4}$ Zambia Agriculture Research Institute (ZARI), Lusaka, Zambia; ${ }^{5}$ The National Smallholder Farmers' Association of Malawi (NASFAM), Lilongwe, Malawi; ${ }^{6}$ Lilongwe University of Agriculture and Natural Resources (Bunda Campus), Lilongwe, Malawi; ${ }^{7}$ Food, Agriculture and Natural Resources Policy Analysis Network, Pretoria, RSA; ${ }^{8}$ Forum for Agricultural Research in Africa (FARA), Accra, Ghana.

*Corresponding email: alimbikani@gmail.com

\section{Abstract}

Timely drying of groundnuts is important after harvest. In most parts of sub-Saharan Africa, moisture content reduction is practically achieved by solar drying. In particular, the groundnuts are traditionally cured in the field using the inverted windrow drying technique. Recently, the Mandela cock technique, a ventilated stack of groundnut plants with a chimney at the center, has 
been introduced in the southern Africa region with the aim of reducing moisture content and the risk of aflatoxin contamination. An on-farm study was conducted in Malawi to compare the effectiveness of the Mandela cock and Windrow drying techniques with respect to aflatoxin control. For two consecutive years, farmers $(2016, n=29 ; 2017 ; n=26)$ were recruited to test each of the two drying techniques. A mixed-design ANOVA showed that the Mandela cock groundnut drying technique led to significantly $(p<0.001)$ higher aflatoxin levels in groundnut seed compared to the traditional inverted windrow drying $(5.7 \mu \mathrm{g} / \mathrm{kg}$, geometric mean vs 2.5 $\mu \mathrm{g} / \mathrm{kg}$ in 2016 and $37.6 \mu \mathrm{g} / \mathrm{kg} v \mathrm{~s} 8.4 \mu \mathrm{g} / \mathrm{kg}$ in 2017). The present findings clearly demonstrate the need for regulation and technology validation if farmers and consumers are to benefit.

Key words: Aflatoxin, groundnuts, drying, food safety, 'Mandela cock', 'Inverted windrow'.

\section{Introduction}

Aflatoxin contamination in groundnut (Arachis hypogaea), is a serious problem worldwide affecting human health and restricting trade in affected products. Aflatoxins are secondary metabolites produced mainly by Aspergillus flavus and A. parasiticus and have been linked to immunosuppressive, hepatotoxic, carcinogenic, mutagenic, and teratogenic effects in laboratory animals (Wong and Hsieh, 1976; Williams et al. 2004; Osward et al., 2005; El-Nahla et al., 2013), and the same problems could occur in humans. The aflatoxigenic fungi may invade and contaminate the developing groundnut pods with aflatoxin prior to lifting following severe lateseason drought stress (Griffin and Garren, 1976; Dorner et al., 1989; Dorner et al., 1998; Guo et. al, 2009), pod damage by insects (Widstrom, 1979) and over maturity (McDonald, 1970; Mehan et al., 1986; Dorner et al., 1989). However, in the developing world, most aflatoxin contamination 
occurs at harvest and during drying and subsequent storage (Wild and Hall, 2000; Williams et al., 2004; Turner et al., 2005). Aflatoxin in groundnuts leads to reduced crop yields as contaminated seed has to be discarded and farmers receive less income from reduced sales.

In developing countries within the tropics, groundnuts are often harvested under humid, warm and rainy conditions. The majority of farmers lack drying equipment (Matumba et al., 2017a) and rely on sun-drying (solar drying), often placing the harvested groundnuts on ground in contact with soil where exposure to contamination is much more likely. The groundnuts are often manually lifted from the soil with the aid of a hand hoe. The groundnut plants (with pods intact) are then windrowed in the field until lower storage moisture levels are achieved. A windrow is a long low ridge or line of harvested crop plants, designed to achieve the best conditions for drying. The two types of windrow can be described as follows: 1) a random windrow where plants are left to dry haphazardly with most of the pods covered by foliage; and, 2) an inverted windrow where the plants are inverted to expose the pods to sunlight (Porter and Garren, 1970) (Figure 1).

Drying of groundnuts using the inverted windrow technique was found to be more rapid and less favourable for mould development than random windrows (Porter and Garren, 1970; Porter and Wright, 1971). Subsequently, inverted windrows have been advocated by most extension agents worldwide. Recently, the Mandela $\operatorname{cock}^{1}$ groundnut drying technique (Figure 2), which involves windrowing the groundnuts for a few days followed by stacking of the plants, has been introduced in the southern African region and is now in widespread use by small scale groundnut farmers

\footnotetext{
${ }^{1}$ A different spelling (Mandela 'cork') exists on the web (African Institute of Corporate Citizenship (AICC), 2014; ICRISAT Open Access Repository, 2012).
} 
following its dissemination by government and non-government actors. There is limited information regarding the origin of the practice and the name. It appears that the name 'Mandela cock' stems from a haycock, which refers to a small cone-shaped pile of hay that has been left in the field until it is dry enough to be carried to the hayrick. The use of a 'cock' to dry groundnut is highlighted in an FAO groundnut publication of a decade and a half ago as one of the traditional groundnut drying techniques employed in Nigeria and certain parts of southern Africa (Nautiyal, 2002). However, the roots of the 'Mandela' prefix are not clear. Perhaps the inclusion of the Mandela name is in recognition of the fact that the practice was developed in South Africa.

According to a recently published groundnut instruction manual, the Mandela cock technique involves windrowing groundnuts for 1-4 days (to rapidly reduce moisture) followed by constructing a circular platform of soil about $1 \mathrm{~m}$ in diameter which supports a single layer of inverted plants compressed together filling the whole platform (AICC, 2014). Subsequently, more bunches of groundnut plants are added horizontally (with pods facing inward) on the periphery of the circle leaving a chimney at the center. In each successive layer, the diameter of the chimney is reduced and the pods are arranged towards the center of the stack until a maximum height of about $1.5 \mathrm{~m}$ is attained. The chimney is then closed with one or two plants and the stack is left uncovered in the field for about 2-4 weeks depending on humidity, temperature and wind movement. Proponents of the Mandela cock drying technique claim that it reduces the risk of aflatoxin contamination as there is rapid initial moisture reduction from the windrowing step. It is also believed that stacking in a cock prevents rain water ingress, although we were unable to find evidence to support this view. 
To address this gap in knowledge the current study was carried out to systematically compare the performance of the two techniques (inverted windrow and Mandela cock technique) with respect to aflatoxin incidence. The primary objective was to establish whether there is a difference in the total level of aflatoxin in groundnuts dried using the two techniques. A further aim was to identify whether aflatoxin levels differed between years and whether any treatment differences were consistent over time. It is expected that the findings of the study will help to reduce yield losses in groundnuts due to rot and aflatoxin accumulation.

\section{Materials and Methods}

Site Selection and Recruitment of Participant Farmers

A total of 29 randomly selected smallholder farmers were recruited from Lilongwe (Mpenu and Mitundu Extension Planning Areas (EPA), 7 farms), Mchinji (Chiosha EPA, 13 farms) and Dowa (Mponera EPA, 9 farms) districts during the 2015/16 growing season (under rain fed conditions). The experiment was repeated during the 2016/17 season in 26 farms in Mikundi EPA in Mchinji district. The site selection for the 2016/17 growing season was based on logistical reasons and the number of participating farms depended on the willingness of the farmers to participate in the

study. The multi-locational farmer-managed trials were conducted over two growing seasons in order to take into consideration the variability that could arise from diversity of stack architecture (chimney diameter, stack height, foliage density), groundnut moisture levels, and environmental conditions including field fungal population.

Groundnut Field Establishment and Crop Management 
Groundnuts of the cultivar Virginia bunch CG 7 (the most popular variety in Malawi which was released in 1990) were freely distributed to all participating farmers. Seeds were planted by all the farmers with the first planting rains (approximately 20-30 mm). Malawi has one rainfall season that stretches from October/December to April/May. Based on the rainfall pattern, in the 2015/16 growing season, groundnut was planted between 20 and 22 December 2015, while during the 2016/17 growing season, the crop was planted between 27 and 29 November, 2016.

Agronomic practices recommended for Virginia-type groundnuts were used (Ministry of Agriculture, 1993). Soil fungicides and nematicides were not used. Further, no inorganic fertilizers were applied as is the practice in Malawi. All these practices were applied by the farmers themselves with minimal guidance from the extension worker. Plants were harvested between 125-140 days after planting. After harvest the groundnuts were dried in the field using two techniques: 1) inverted windrow (hereafter referred to as windrow); and, 2) the Mandela cock technique. This was done under the guidance of an extension worker. The crops were harvested in May in 2016 and April in 2017, respectively, and the cropping seasons are hereafter referred to as '2016' and '2017'..

In 2016 groundnuts from the two treatments were stripped from the vegetation on the same day on each individual farm having been dried in the field for roughly 3 weeks as stipulated in the technology instruction manual (African Institute of Corporate Citizenship (AICC), 2014; ICRISAT Open Access Repository, 2012). In 2017 the groundnuts from the two treatments were stripped from the vegetation at different times as deemed appropriate by the individual farmers. 


\section{On-farm sampling of groundnuts}

For each treatment, the harvested pods were pooled, mixed thoroughly, and a $5 \mathrm{~kg}$ aggregate sample was extracted by trained laboratory personnel. A pair was recorded for each farm. This provided 29 paired samples in 2016 and 26 paired samples in 2017. By using paired samples, the effect of farm to farm variation in aflatoxin levels on determining differences between the two treatments is minimized (Macfadyen et al., 2009; Purtauf et al., 2005). In all cases, aflatoxin was extracted from a $25 \mathrm{~g}$ test portion drawn from the milled aggregated sample of kernels $(5 \mathrm{~kg}$ of pods yields about $3.5 \mathrm{~kg}$ of kernels) in order to reduce sampling error (Whitaker et al., 1974; 1995; Giesbrecht and Whitaker, 1998).

\section{Quantification of aflatoxin}

The shelled groundnut samples were measured by VICAM immunoaffinity column cleanup coupled with high-performance liquid chromatography and on-line post-column photochemical derivatization-fluorescence detection (IAC-HPLC-PCD-FLD). The IAC-HPLC-PCD-FLD technique used for aflatoxin analysis was similar to that described by Matumba et al., (2014). Limits of quantification of the aflatoxin analytical method were $0.2 \mu \mathrm{g} / \mathrm{kg}$ for aflatoxin $\mathrm{B}_{1}\left(\mathrm{AFB}_{1}\right)$ and $\mathrm{AFG}_{1}$ and $0.1 \mu \mathrm{g} / \mathrm{kg}$ for $\mathrm{AFB}_{2}$ and $\mathrm{AFG}_{2}$. The results for the four individual aflatoxins $\left(\mathrm{AFB}_{1}\right.$, $\mathrm{AFB}_{2}, \mathrm{AFG}_{1}$ and $\mathrm{AFG}_{2}$ ) were presented graphically. However, in most of the discussion, we express total aflatoxin as the sum of these analogs.

Statistical Analyses 
After a log-transformation to improve normality of the data, the Total Aflatoxins variable was subjected to a two-factor mixed-design ANOVA in R (version 3.4.4) to test whether aflatoxin accumulation was influenced by the postharvest treatment or the year. As the two treatments were applied to part of the same harvest from each farmer, a paired-sample analysis was used (withinsubject in a multi-factor analysis) for treatment (Windrow or Mandela cock) as the within-subject factor. The year was the between-subject factor as, if groundnuts from each farmer were divided in two lots for the two postharvest treatments in each year, different farmers were involved in each year. Therefore, the analysis also allowed us to test whether there was an interaction between the two factors.

\section{Results}

With the exception of one sample (dried using the windrow technique, in 2016), all the samples from the field experiment contained aflatoxins with levels reaching as high as $799 \mu \mathrm{g} / \mathrm{kg}$ in Mandela cock dried groundnuts and $290 \mu \mathrm{g} / \mathrm{kg}$ in windrow dried groundnuts (Table 1). Although the ranges of aflatoxin content overlapped between samples dried using windrow and Mandela cock in both years (2016 and 2017), the results of the mixed-design ANOVA show that there was a large difference between the treatments $(\mathrm{p}<0.001)$, and between the years $(\mathrm{p}<0.001)$, with 2017 showing higher levels of total aflatoxins in both treatments, and the Mandela cock showing higher levels of total aflatoxins in both years (Table 1). There was no statistically significant interaction between year and treatment, meaning that the effect of treatment does not change between the two years and conversely, the year effect is consistent regardless of the treatment (Table 2).

Due to natural variability of aflatoxins, some samples showed very high values (e.g. 799 and 420 $\mu \mathrm{g} / \mathrm{kg}$ ). Even after a log transformation, these could normally be considered outliers in statistical 
analyses, but had to be kept in the analysis as they are the natural occurrence of aflatoxins. Despite the prevalence of a few samples with extremely high aflatoxin content in 2016, the geometric means for aflatoxin levels for both treatments were comparatively lower than in 2017. Correspondingly, relatively higher proportions of samples (in both the Mandela cock and windrow treatments) in 2017 exceeded the regulatory limits. However, treatment-wise, a higher proportion of groundnut samples that were dried using Mandela cock than those that were dried using windrow exceeded the aflatoxin limit used in Malawi $(3 \mu \mathrm{g} / \mathrm{kg}), \mathrm{EU}(4 \mu \mathrm{g} / \mathrm{kg})$, most developing countries (10 $\mu \mathrm{g} / \mathrm{kg})$, and the USA (20 $\mu \mathrm{g} / \mathrm{kg}$ ) (Table 1). Notably, $31 \%$ and $100 \%$ of the samples drying using Mandela techniques in 2016 and 2017 respectively exceeded the $10 \mu \mathrm{g} / \mathrm{kg}$ limit. Comparatively, less than half of these proportions exceeded $10 \mu \mathrm{g} / \mathrm{kg}$ limit in samples that were dried using windrow (Table 1).

Similar to the occurrence pattern or the aflatoxin analogs $\left(\mathrm{AFB}_{1}, \mathrm{AFB}_{2}, \mathrm{AFG}_{1}\right.$, and $\left.\mathrm{AFG}_{2}\right)$ previously published for maize, groundnuts, pigeon pea and cowpea from Malawi (Matumba et al., 2015 and 2017b), $\mathrm{AFB}_{1}$ was the most frequently detected toxin and occurred in all but one aflatoxin positive sample. $\mathrm{AFG}_{1}$ was the second most frequently detected toxin and was present in $84 \%$ of aflatoxin positive samples. Further, $\mathrm{AFG}_{1}$ was detected in the aflatoxin positive sample in which $\mathrm{AFB}_{1}$ was absent. $\mathrm{AFB}_{2}$ and $\mathrm{AFG}_{2}$ always co-occurred with $\mathrm{AFB}_{1}$ and $\mathrm{AFG}_{1}$, respectively and in every case the pattern was $\mathrm{AFB}_{1}>\mathrm{AFB}_{2}$ and $\mathrm{AFG}_{1}>\mathrm{AFG}_{2}$. In $33.6 \%$ of the aflatoxin positive groundnut samples, $\mathrm{AFG}_{1}$ concentration exceeded $\mathrm{AFB}_{1}$. The mean relative percentages to which $\mathrm{AFB}_{1}, \mathrm{AFB}_{2}, \mathrm{AFG}_{1}$, and $\mathrm{AFG}_{2}$ contributed to the total aflatoxin content (100\%) in the groundnut samples were 54.6\%, $4.0 \%, 39.4 \%$, and 2.0\%, respectively (Figure 4 and 5). 


\section{Discussion}

The present farmer-managed experiment compared the performance of Mandela cock and windrow groundnut drying techniques with regards to aflatoxin contamination of groundnut seed. The study limitations that the study neither measured the moisture of groundnuts during drying process nor attempted to optimize the timeliness of field drying and that the windrows and the Mandela cocks were manually constructed by the farmers themselves which may have contributed to non-uniformity in the way they were constructed, the present findings suggest conclusively that the Mandela cock groundnut drying technique results in higher aflatoxin contamination compared to the windrow technique. These findings could significantly contribute to the development of strategies managing groundnut rot and aflatoxin accumulation during drying under smallholder setting, thus reducing yield losses.

It is likely that the higher aflatoxin contamination in Mandela cock treated kernels resulted from the humid conditions that occurred during curing in the stack. In the Mandela cock technique, the plants are piled up and as a consequence, the pods are not exposed to sunlight. This, coupled with poor air circulation, prolongs drying thereby allowing moulds to proliferate.

The effect of light itself on mould proliferation is both complex and unclear. While numerous studies have reported an inhibitory effect of light on mould growth (Murdoch et al., 2013; SchmidtHeydt et al., 2011; Ray et al., 2009; Bayram et al., 2008; Cotty and Misaghi, 1985; Rotem et al., 1985; Häggblom and Unestam, 1979), some have showed the promotional effect (Matić et al., 2013; Fanelli et al., 2012; Oueslati et al., 2010) due to variation in matrice nutritional composition (Atoui et al., 2010), temperature (Rotem and Aust, 1991), relative humidity (Atalla et al., 2004) 
and type of genera or species (Cheong et al., 2016; Atalla et al., 2004). Importantly, in similar ways, these conditions influence mycotoxin production of the fungi (Arias et al., 2012; Desmond et al., 2008; Xu et al., 2007) including aflatoxin (Klich, (2007).

Data on the effect of light on aflatoxigenic fungi and toxin production during drying of groundnuts is sparse. Porter and Garren, (1970) observed a steady reduction of isolation frequency of A. flavus during drying of groundnuts in windrows. Similar trends were reported by McDonald and Harkness, (1964) and Jackson, (1965). But it is likely that the reduction of the aflatoxigenic fungi isolation frequencies resulted from an interactive effect of light and water activity over the drying period and not light alone. Do these findings help to explain the significant difference between aflatoxin levels in the windrow and the Mandela cock found in the present study?

As is very often the case with aflatoxin measurements, the values recorded in this study were highly variable. The relatively low levels of aflatoxin contamination encountered in some samples that were dried using the Mandela cock technique indicate that under certain conditions the technique may yield groundnuts with acceptable aflatoxin levels. With regard to the small number of groundnut samples with exceptionally high levels of aflatoxins in windrowed groundnuts, this may have resulted from the contact of groundnut pods with soil or covering by foliage (as was noted by farmers in several cases). The lifting and inverting of the groundnut crop was performed manually and it is likely to have been imperfect considering the physical effort involved. This could also be due to the fact that the farmers were busy with other activities and were not able to devote enough time to do the job with the necessary care. Further, the bunch stature of the Virginia 
CG 7 variety used in the experiment $(20-30 \mathrm{~cm}$ tall) led to lodging in high winds and pods came into contact with soil.

The comparatively greater aflatoxin contamination problem experienced in 2017 than in 2016, as indicated by a higher proportion of groundnut samples exceeding the regulatory limit and revealed by the mixed-design ANOVA, was most likely due to the environmental differences between the years (Figure 3). Unlike in 2016 when there was no rainfall during drying of groundnuts in the field, in 2017 there were multiple episodes of rainfall in April and traces of rainfall in May which consequently increased the level of aflatoxin contamination.

Generalized global occurrence ratios of the four aflatoxins $\left(\mathrm{AFB}_{1}+\mathrm{AFB}_{2}+\mathrm{AFG}_{1}+\mathrm{AFG}_{2}\right)$ reported earlier (European Commission EC, 2012; Kensler et al., 2011; Van Egmond and Jonker, 2004) indicate that $A F B$ exceeds half of the sum of the aflatoxins and that $\mathrm{AFB}_{2}$ and $\mathrm{AFG}_{2}$ occur in the lowest concentrations. Interestingly, the present unusual aflatoxin profile corroborate published aflatoxin occurrence patterns in maize, cowpea, pigeon pea and groundnut samples from Malawi, with $\mathrm{AFG}_{1}$ found frequently at equal or higher levels than $\mathrm{AFB}_{1}$ (Matumba et al., 2015, 2017). This pattern is also apparent in peanut butter samples from neighbouring Zambia (Matumba et al., manuscript in preparation) and in a publication made on samples from neighbouring Mozambique where average $\mathrm{AFB}_{1}$ and $\mathrm{AFG}_{1}$ concentrations were comparable (Warth et al., 2012). Until now, aflatoxigenic fungal strains have not been fully characterized in Malawi (and the region). It is therefore tempting to speculate that the aflatoxigenic strains responsible for such uncommon aflatoxin profiles may be shared with neighboring region, hence the similarity of the co-occurrence pattern of the aflatoxin analogs. Similar patterns have been 
reported in nuts of Brazilian origin (Oliveira et al., 2009; Olsen et al., 2008) where through fungal isolation, the authors concluded that the toxins were produced by Aspergillus nomius.

\section{Conclusion and Future Perspectives}

This study has provided the first published data on the efficacy of the Mandela cock technique compared with the conventional technique of drying groundnuts in inverted windrows as a means of managing aflatoxin contamination in Malawi. It is important to highlight that the study has several limitations. First, the windrows and the Mandela cocks were manually constructed by the farmers themselves and therefore there may have been lack of uniformity in the way they were constructed. However this gave a realistic representation of the situation on the farms. Second, we did not measure the moisture of groundnuts and did not attempt to optimize the timeliness of field drying. The groundnuts were either left to dry as stipulated in the manual or this was done at the discretion of the farmers. The groundnuts may have been left longer in the field than is necessary and this may have contributed towards high aflatoxin contamination. Nonetheless, the findings have clearly demonstrated technical flaws in the two drying techniques, particularly in the Mandela cock. Based on the findings of the present study is strongly recommended that, before further efforts are made to promote the Mandela cock drying technique among groundnut farms across Africa, further research be conducted to modify/improve the approach. Considering the high and overlapping aflatoxin levels in groundnuts from the Mandela cock and window techniques, a search for a more efficient alternative drying techniques is merited. The rainfall pattern has become unpredictable in most parts of sub-Saharan Africa, and it is increasingly important that farmers use drying techniques that mitigate the risk of aflatoxin contamination by allowing speedy evaporation 
or reducing the wetting of the nuts; for example, stripping groundnuts and drying them on tarpaulins or, where resources allow, using forced air driers.

\section{Conflict of interest statement}

We declare that we have no conflict of interest.

\section{Acknowledgements}

This research was funded with the support of the European Commission's Directorate General for Development and International Cooperation (DG-DevCo) through the Platform for African European Partnership on Agricultural Research for Development (PAEPARD) -supported project 'Stemming aflatoxin pre- and post-harvest waste in the groundnut value chain (GnVC)'. Aflatoxin analysis was supported by the World Bank through the Agricultural Productivity Program for Southern Africa (APPSA) project number MC-P04-2014. The authors also acknowledge the donation of an HPLC system to Chitedze Mycotoxin Laboratory by the EU, through a SADCFood Safety Capacity Building on Residues Control Project.

\section{Disclaimer}

This publication reflects the views only of the authors, and the European Union cannot be held responsible for any use which may be made of the information contained therein.

\section{References}

African Institute of Corporate Citizenship (AICC), 2014). Harmonized groundnut production manual for Malawi (unpublished). Retrieved from http://os.aiccafrica.org/media/Groundnut\%20manual\%20\%20-FINAL.pdf 
Arias, S.L., Theumer, M.G., Mary, V.S. and Rubinstein, H.R., 2012. Fumonisins: Probable role as effectors in the complex interaction of susceptible and resistant maize hybrids and Fusarium verticillioides. Journal of Agricultural and Food Chemistry 60: 5667-5675.

Atalla, M. M., Hassanein, N. M., El-Beih, A. A., \& Youssef, Y. A. (2004). Effect of fluorescent and UV light on mycotoxin production under different relative humidities in wheat grains. International Journal of Agriculture and Biology, 6(6), 1006-1012.

Atoui, A., Kastner, C., Larey, C. M., Thokala, R., Etxebeste, O., Espeso, E. A., ... \& Calvo, A. M. (2010). Cross-talk between light and glucose regulation controls toxin production and morphogenesis in Aspergillus nidulans. Fungal Genetics and Biology, 47(12), 962-972.

Aziz, N.H. \& Moussa, L.A. (1997). Influence of white light, near UV irradiation and other environmental conditions on the production of aflatoxin B1 by Aspergillus flavus and ochratoxin A by Aspergillus ochraceus. Nahrung 41:150-154

Bayram, Ö, Krappmann, S., Ni, M., Bok, J. W., Helmstaedt, K., Valerius, O., ... \& Braus, G. H. (2008). VelB/VeA/LaeA complex coordinates light signal with fungal development and secondary metabolism. Science, 320 (5882), 1504-1506.

Cheong, K. K., Strub, C., Montet, D., Durand, N., Alter, P., Meile, J. C., ... \& Fontana, A. (2016). Effect of different light wavelengths on the growth and ochratoxin A production in Aspergillus carbonarius and Aspergillus westerdijkiae. Fungal biology, 120(5), 745-751.

Chouraisia, H.K. \& Roy, A.K. (1991). Effect of temperature, relative humidity and light on aflatoxin B1 production in neem and Datura seeds. International Journal of Pharmacognosy 3:197-202

Cotty, P. J., \& Misaghi, I. J. (1985). Effect of light on the behavior of Alternaria tagetica in vitro and in vivo. Phytopathology, 75(3), 366-370.

Desmond, O.J., Manners, J.M., Schenk, P.M., Maclean, D.J. and Kazan, K., 2008. Gene expression analysis of the wheat response to infection by Fusarium pseudograminearum. Physiological and Molecular Plant Pathology 73: 40-47.

Dorner, J. W., Cole, R. J., \& Blankenship, P. D. (1998). Effect of inoculum rate of biological control agents on preharvest aflatoxin contamination of peanuts. Biological Control, 12(3), 171-176. 
Dorner, J. W., Cole, R. J., Sanders, T. H., \& Blankenship, P. D. (1989). Interrelationship of kernel water activity, soil temperature, maturity, and phytoalexin production in preharvest aflatoxin contamination of drought-stressed peanuts. Mycopathologia, 105(2), 117-128.

El-Nahla SM, Imam, HM, Moussa EA, Ibrahim AM, Ghanam AR (2013) Teratogenic effects of aflatoxin in Rabbits (Orycto-laguscuniculus). Journal of Veterinary Anatomy 6: 67-85

European Commission (EC). (2010). Commission regulation (EU) no 165/2010 of 26 February 2010, amending regulation (EC) no 1881/2006 setting maximum levels for certain contaminants in foodstuffs as regards aflatoxin. Official Journal of the European Union L, 50, 8-2.

European Commission (EC) (2012) Regulation (EU) No 1058/2012 of 12 November 2012 amending Regulation (EC) No 1881/2006 as regards maximum levels for aflatoxins in dried figs. Official Journal of the European Union L 313:14-15

Fanelli, F., Schmidt-Heydt, M., Haidukowski, M., Geisen, R., Logrieco, A., \& Mulè, G. (2012). Influence of light on growth, fumonisin biosynthesis and FUM1 gene expression by Fusarium proliferatum. International Journal of Food Microbiology, 153(1), 148-153.

FAO. (2004). Food Agriculture Organization of the United Nations, Food and Nutrition Paper No. 81: Worldwide regulations for mycotoxins in food and feed in 2003. Rome, Italy

Giesbrecht, F. G., \& Whitaker, T. B. (1998). Investigations of the problems of assessing aflatoxin levels in peanuts. Biometrics, 739-753.

Griffin, G. J. \& K. H. Garren, 1976. Colonization of aerial peanut pegs by Aspergillus flavus and A. niger group fungi under field conditions. Phytopathology 66:1161-1162.

Guo, B., Yu, J., Holbrook, C. C., Cleveland, T. E., Nierman, W. C., \& Scully, B. T. (2009). Strategies in prevention of preharvest aflatoxin contamination in peanuts: aflatoxin biosynthesis, genetics and genomics. Peanut Science, 36(1), 11-20.

Häggblom, P., \& Unestam, T. (1979). Blue light inhibits mycotoxin production and increases total lipids and pigmentation in Alternaria alternata. Applied and Environmental Microbiology, 38(6), 1074-1077.

ICRISAT Open Access Repository, 2012. Collective action and reaction: Market-based groundnut development in Malawi [ICRISAT Eastern and Southern Africa 2011 Highlights]. http://oar.icrisat.org/6659/1/Collective_action_and_reaction.pdf (Accessed 22 $2^{\text {nd }}$ February 2017) 
Jackson, C. R. 1965. Growth of Aspergillus flavus and other fungi in windrowed peanuts in Georgia. Tropical Science, 7:27-34.

Kensler, T. W., Roebuck, B. D., Wogan, G. N., \& Groopman, J. D. (2010). Aflatoxin: a 50-year odyssey of mechanistic and translational toxicology. Toxicological sciences, 120(suppl_1), S28-S48.

Klich, M. A. (2007). Environmental and developmental factors influencing aflatoxin production by Aspergillus flavus and Aspergillus parasiticus. Mycoscience, 48(2), 71-80.

Macfadyen, S., Gibson, R., Polaszek, A., Morris, R. J., Craze, P. G., Planqué, R., ... \& Memmott, J. (2009). Do differences in food web structure between organic and conventional farms affect the ecosystem service of pest control? Ecology Letters, 12(3), 229-238.

Matić, S., Spadaro, D., Prelle, A., Gullino, M. L., \& Garibaldi, A. (2013). Light affects fumonisin production in strains of Fusarium fujikuroi, Fusarium proliferatum, and Fusarium verticillioides isolated from rice. International Journal of Food Microbiology, 166(3), $515-523$.

Matumba, L., Monjerezi, M., Biswick, T., Mwatseteza, J., Makumba, W., Kamangira, D., \& Mtukuso, A. (2014). A survey of the incidence and level of aflatoxin contamination in a range of locally and imported processed foods on Malawian retail market. Food Control, 39, 87-91.

Matumba, L., Singano, L., Pungulani, L., Mvula, N., Matumba, A., Singano, C., \& Matita, G. (2017b). Aflatoxins, discolouration and insect damage in dried cowpea and pigeon pea in Malawi and the effectiveness of flotation/washing operation in eliminating the aflatoxins. Mycotoxin Research, 33(2), 129-137.

Matumba, L., Sulyok, M., Njoroge, S. M., Ediage, E. N., Van Poucke, C., De Saeger, S., \& Krska, R. (2015). Uncommon occurrence ratios of aflatoxin B1, B2, G1, and G2 in maize and groundnuts from Malawi. Mycotoxin Research, 31(1), 57-62.

Matumba, L., Van Poucke, C., Njumbe Ediage, E., \& De Saeger, S. (2017a). Keeping mycotoxins away from the food: does the existence of regulations have any impact in Africa? Critical Reviews in Food Science and Nutrition, 57(8), 1584-1592.

Matumba, L., Singano, L., Pungulani, L., Mvula, N., Matumba, A., Singano, C., \& Matita, G. (2017). Aflatoxins, discolouration and insect damage in dried cowpea and pigeon pea in 
Malawi and the effectiveness of flotation/washing operation in eliminating the aflatoxins. Mycotoxin Research, 33(2), 129-137.

Matumba, L., Sulyok, M., Njoroge, S. M., Ediage, E. N., Van Poucke, C., De Saeger, S., \& Krska, R. (2015). Uncommon occurrence ratios of aflatoxin B 1, B 2, G 1, and G 2 in maize and groundnuts from Malawi. Mycotoxin Research, 31(1), 57-62.

McDonald, D. (1970). Fungal infection of groundnut fruit after maturity and during drying. Transactions of the British Mycological Society, 54(3), 461-472.

McDonald, D., and C. Harkness. 1964. Growth of Aspergillus flavus and production of aflatoxin in groundnuts. Part IV. Tropical Science, 6:12-27.

Mehan, V. K., McDonald, D., Ramakrishna, N., \& Williams, J. H. (1986). Effects of Genotype and Date of Harvest on Infection of Peanut Seed by Aspergillus flavus and Subsequent Contamination with Aflatoxin. Peanut Science, 13(2), 46-50.

Ministry of Agriculture (MOA) 1993. Guide to Agricultural Production in Malawi. Extension Aids Branch, Lilongwe, Malawi.

Murdoch, L. E., McKenzie, K., Maclean, M., Macgregor, S. J., \& Anderson, J. G. (2013). Lethal effects of high-intensity violet 405-nm light on Saccharomyces cerevisiae, Candida albicans, and on dormant and germinating spores of Aspergillus niger. Fungal Biology, 117(7), 519-527.

Nautiyal, P. C. (2002). Groundnut: post-harvest operations. Food and Agriculture Organization of the United Nations.[online] Available from http://www.fao.org/3/a-av005e.pdf (Accessed on January 20, 2017).

Oliveira, C. A., Gonçalves, N. B., Rosim, R. E., \& Fernandes, A. M. (2009). Determination of aflatoxins in peanut products in the northeast region of São Paulo, Brazil. International journal of molecular Sciences, 10(1), 174-183.

Olsen, M., Johnsson, P., Möller, T., Paladino, R., \& Lindblad, M. (2008). Aspergillus nomius, an important aflatoxin producer in Brazil nuts?. World Mycotoxin Journal, 1(2), 123-126.

Oswald, I. P., Marin, D. E., Bouhet, S., Pinton, P., Taranu, I., \& Accensi, F. (2005). Immunotoxicological risk of mycotoxins for domestic animals. Food additives and contaminants, 22(4), 354-360. 
Oueslati, S., Lasram, S., Ramos, A. J., Marin, S., Mliki, A., Sanchis, V., \& Ghorbel, A. (2010). Alternating temperatures and photoperiod effects on fungal growth and ochratoxin A production by Aspergillus carbonarius isolated from Tunisian grapes. International Journal of Food Microbiology, 139(3), 210-213.

Porter, D. M., \& Garren, K. H. (1970). Endocarpic microorganisms of two types of windrow-dried peanut fruit (Arachis hypogaea L.). Applied Microbiology, 20(1), 133-138.

Porter, D. M., \& Wright, F. S. (1971). Proliferation of Aspergillus flavus in artificially infested windrow dried peanut fruits in Virginia. Phytopathology, 61(10), 1194-1197.

Purtauf, T., Roschewitz, I., Dauber, J., Thies, C., Tscharntke, T., \& Wolters, V. (2005). Landscape context of organic and conventional farms: influences on carabid beetle diversity. Agriculture, Ecosystems \& Environment, 108(2), 165-174.

Ray, P. Sushilkumar and Pandey AK. (2009). Influence of photoperiod on growth and mycoherbicidal potential of Alternaria alternata, a biocontrol agent of waterhyacinth. Journal of Mycology and Plant Pathology 39(3), 458-461.

Rotem, J., \& Aust, H. J. (1991). The effect of ultraviolet and solar radiation and temperature on survival of fungal propagules. Journal of Phytopathology, 133(1), 76-84.

Rotem, J., Wooding, B., \& Aylor, D. E. (1985). The role of solar radiation, especially ultraviolet, in the mortality of fungal spores. Phytopathology, 75(5), 510-514.

Schmidt-Heydt, M., Rüfer, C., Raupp, F., Bruchmann, A., Perrone, G., \& Geisen, R. (2011). Influence of light on food relevant fungi with emphasis on ochratoxin producing species. International Journal of Food Microbiology, 145(1), 229-237.

Torres, A. M., Barros, G. G., Palacios, S. A., Chulze, S. N., \& Battilani, P. (2014). Review on preand post-harvest management of peanuts to minimize aflatoxin contamination. Food Research International, 62, 11-19.

Turner, P. C., Sylla, A., Gong, Y. Y., Diallo, M. S., Sutcliffe, A. E., Hall, A. J., \& Wild, C. P. (2005). Reduction in exposure to carcinogenic aflatoxins by postharvest intervention measures in West Africa: a community-based intervention study. The Lancet, 365(9475), 1950-1956.

Van Egmond, H. P., \& Jonker, M. A. (2004). Worldwide regulations on aflatoxins - the situation in 2002. Journal of Toxicology: Toxin Reviews, 23(2-3), 273-293. 
Widstrom, N. W. (1979). The role of insects and other plant pests in aflatoxin contamination of corn, cotton, and peanuts - a review. Journal of Environmental Quality, 8(1), 5-11.

Wild, C. P., \& Hall, A. J. (2000). Primary prevention of hepatocellular carcinoma in developing countries. Mutation Research/Reviews in Mutation Research, 462(2), 381-393.

Williams, J. H., Phillips, T. D., Jolly, P. E., Stiles, J. K., Jolly, C. M., \& Aggarwal, D. (2004). Human aflatoxicosis in developing countries: a review of toxicology, exposure, potential health consequences, and interventions. The American journal of clinical nutrition, 80(5), 1106-1122.

Whitaker, T. B., Dickens, J. W., \& Monroe, R. J. (1974). Variability of aflatoxin test results. Journal of the American Oil Chemists' Society, 51(5), 214-218.

Whitaker, T. B., Springer, J., Defize, P. R., \& Coker, R. (1995). Evaluation of sampling plans used in the United States, United Kingdom, and The Netherlands to test raw shelled peanuts for aflatoxin. Journal of AOAC International, 78(4), 1010-1018.

Warth, B., Parich, A., Atehnkeng, J., Bandyopadhyay, R., Schuhmacher, R., Sulyok, M., \& Krska, R. (2012). Quantitation of mycotoxins in food and feed from Burkina Faso and Mozambique using a modern LC-MS/MS multitoxin method. Journal of Agricultural and Food Chemistry, 60(36), 9352-9363.

Wong, J.J. \& Hsieh, D.P. (1976) Mutagenicity of aflatoxins related to their metabolism and carcinogenic potential. Proceedings of the National Academy of Sciences of the United States of America 73 (7), 2241-2244

Xu, X. M., Monger, W., Ritieni, A., \& Nicholson, P. (2007). Effect of temperature and duration of wetness during initial infection periods on disease development, fungal biomass and mycotoxin concentrations on wheat inoculated with single, or combinations of, Fusarium species. Plant Pathology, 56(6), 943-956. 